\title{
Evaluation of Urinary Tryptophan Metabolite Levels in Non-diabetic Compared to Diabetic Rats
}

\author{
Loredana Elena OLAR*, Razvan ȘTEFAN, Anisia CĂȚIOIU, Ionel PAPUC \\ University of Agricultural Sciences and Veterinary Medicine, Faculty of Veterinary Medicine, 3-5 Calea \\ Manastur Street, 400372, Cluj-Napoca, Romania \\ *corresponding author: loredana.olar@usamvcluj.ro
}

Bulletin UASVM Veterinary Medicine 74(2)/2017

Print ISSN 1843-5270; Electronic ISSN 1843-5378

doi:10.15835/buasvmcn-vm:0021

\begin{abstract}
Diabetes mellitus is one of the most common metabolic disorders in animals. Thus, currently, it is imperative to introduce non-invasive, economical and rapid methods for the investigation of diabetes in animals. In this study, the urine samples collected from 10 non-diabetic and 10 streptozotocin-induced diabetic rats were investigated by the spectrofluorimetric technique. Emission spectra for the urine samples were obtained following an excitation wavelength of 280 and $400 \mathrm{~nm}$. The investigated fluorophores were mainly tryptophan metabolites, and significant differences resulted between the mean heights of the emission bands attributed to these fluorophore compounds in diabetic compared to non-diabetic rats. The shape of the spectral windings after the utilization of these two excitation wavelengths was almost similar for diabetic and non-diabetic rats; however, there were some discriminatory elements between the two types of investigated samples. In conclusion, the obtained urine fluorescence spectra allow a clear differentiation between diabetic and non-diabetic rats.
\end{abstract}

Keywords: urine, spectrofluorimetry, diabetes, tryptophan, urinary metabolites.

\section{INTRODUCTION}

According to some recent surveys, diabetes mellitus is one of the most frequently diagnosed metabolic disorders both in animals and in humans (Wild et al., 2004; Guptill et al., 2003). Therefore, in a recent study regarding the prevalence of diabetes mellitus in 2030, the diabetic population is estimated at 366 million (Wild et al., 2004). Among animals, dogs represent one of the most common species affected by this disease. The number of dogs currently diagnosed with this disease has jumped to 64 out of 10,000 , while in the past 19 out of 10,000 dogs were affected by diabetes (Guptill et al., 2003). This metabolic condition caused by uncontrolled glycemia levels induces both acute and chronic complications (Kitabchi et al., 2009). Thus, a major goal of researchers is to find non-invasive, easy-to-perform and economical methods for the investigation of diabetes mellitus in animals and in humans. In the above view fluorescence spectroscopy is considered to be a potential tool for the investigation of different body diseases, as this technique presents a high sensitivity and is non-invasive (Madhuri et al., 2003).

Many biological tissues and fluids can be investigated by this technique. In the present study, we performed the spectrofluorimetric analysis of urine, given that this biological fluid is known for its role in the diagnosis and prognosis of diseases (Dubayova et al., 2003; Anwer et al., 2009; Rajasekaran et al., 2013). In addition, due to its richness in metabolites, the majority of which are recognized as fluorophores, it is recommended and used for spectrofluorimetric analysis (Dubayova et al., 2003; Kusnir et al., 2005; Perinchery et al., 2010; Anwer et al., 2009; Rajasekaran et al., 2013). Among these fluorophores, tryptophan 
metabolites are the most studied due to their capabilities to show alterations in some metabolic processes (Perincheri et al., 2010; Saude et al., 2007). Despite the fact that numerous studies have analyzed the pathobiochemical characteristics of urine by means of fluorescence spectroscopy (Dubayova et al. 2003), the study of the fluorescence of urine for diabetes diagnosis in particular and disease diagnosis in general is still at the beginning, as evidenced in a recent research article (Rajasekaran et al., 2013).

Therefore, in our study, we used fluorescence spectroscopy in order to investigate the differences between the emission spectra of urine collected from non-diabetic rats and streptozotocininduced diabetic rats. At the same time, we tried to establish the excitation wavelength allowing to make the most significant difference between the two groups of rats. Another important aspect of our study was the assignment of main fluorescence spectral bands to some urine compounds according to known literature data. Furthermore, we evaluated the height of these emission bands in diabetic compared to non-diabetic rats.

\section{MATERIALS AND METHOD}

Animals: We used 10 rats (8 middle-aged and 2 young rats), weighing between $350-500 \mathrm{~g}$. They were housed in two stainless cages, each cage containing 5 rats. The rats were given ad libitum access to food and water. Before induction of diabetes, fasting blood glucose was monitored and ranged between $135 \pm 5 \mathrm{mg} / \mathrm{dl}$ (Akbarzadeh et al., 2007). 24-hour urine samples were collected from all rats included in the control group.

Urine sample collection: Urine samples from non-diabetic rats were collected during the first five days of the experiment. Each rat belonging to the control group was placed in metabolic cages over a 24 hours period and urine was collected. Diabetes was induced immediately after the collection of urine samples. In order to correct the excessive amount of glucose in the blood plasma, on day 2 after induction of diabetes, insulin was administered. The urine of two diabetic rats $(n=2)$ was analyzed on the first day $\left(\mathrm{U}_{0}\right)$ after induction of diabetes, and the rest of the samples $(n=8)$ were collected after administration of a single dose of insulin (from day 3 to day 6) $\left(U_{3-6}\right)$.

Induction of diabetes: Weused streptozotocin for the induction of experimental diabetes in rats.
This drug is a synthetic antineoplastic agent and is classified as an antitumor and chemical antibiotic. In the literature, it is recognized that this drug induces experimental diabetes in three days by destruction of pancreatic $\beta$-cells (Akbarzadeh et al., 2007). In this study, we used a dose of $60 \mathrm{mg} /$ $\mathrm{kg}$ that was administered intravenously. In just three days after streptozotocin administration, the rats with plasma glucose concentrations between 300-500 mg/dl were considered diabetic (Kim et al., 2007). The study protocol was approved by the local Ethics Committee of the University of Agricultural Sciences and Veterinary Medicine, Cluj-Napoca, Romania.

Spectrofluorimetric analysis: The spectrofluorimetric analysis of urine from non-diabetic $(n=10)$ and diabetic rats $(n=10)$ was performed with a Jasco FP 8200 spectrofluorometer. We analyzed $2 \mathrm{ml}$ of urine without prior centrifugation. In order to obtain not only a proper emission for the investigated urinary fluorophores, but also a good comparison between the urine samples collected from non-diabetic and diabetic rats, we used several excitation wavelengths $(280,335$, 370 and $400 \mathrm{~nm}$ ). In this study, we presented the differences between the fluorescence of urine collected from the two groups of rats after performing an excitation with a wavelength of 280 and $400 \mathrm{~nm}$. The emission spectra were recorded in a range from 320 to $600 \mathrm{~nm}$ and from 420 to $650 \mathrm{~nm}$, respectively. The fluorescence data analysis was performed using the Origin Pro 8.5.1 software.

Statistical analysis: Data analyses were made using the software R 2.15.1 for Windows. In order to describe the normal distribution of variables, the Kolmogorov-Smirnov test was used. Normally distributed and continuous data were characterized by means \pm standard deviation. Group comparison was made using the T-test. A $p$ value $<0.05$ was considered statistically significant.

\section{RESULTS AND DISCUSSIONS}

\section{Description of the rats included in the study}

The characteristics of the rats, including age and weight, were provided in the section material and methods. Blood glucose levels were significantly higher in all diabetic rats when compared with non-diabetic controls $(104.4 \pm 4.6$ $\mathrm{mg} / \mathrm{dl} v s .367 .7 \pm 110.2 \mathrm{mg} / \mathrm{dl} ; \mathrm{p}<0.001$ ). 
The use of an excitation wavelength of $280 \mathrm{~nm}$

After performing the excitation at $280 \mathrm{~nm}$, the emission spectra of the urine samples collected from both diabetic and non-diabetic rats presented five emission bands, as follows: at approximately 420, 446, 467, 490 and $520 \mathrm{~nm}$, respectively (Figure $1(\mathrm{~A})$ and $(\mathrm{B})$ ).

Compared with the control group, higher emission bands were found in the rats with induced diabetes (Figure 1(A) and (B)). In addition, from Figure $1(\mathrm{~A})$ it can be observed that the fluorescence emission spectra of normal urine also have a shoulder around $420 \mathrm{~nm}$. In the case of diseased conditions, the weak band of $\sim 420$ $\mathrm{nm}$ is considerably shifted with a prominent peak around $400 \mathrm{~nm}$. Therefore, there is a $20 \mathrm{~nm}$ shift with respect to normal urine. Rajasekaran et al. (2014) reported that the peak at around $400 \mathrm{~nm}$ can be attributed to the tryptophan metabolite indoxyl sulfate. In diabetic rats, the mean of the peak height around $400 \mathrm{~nm}$ was $1312.30 \pm 175.194$, while in the case of non-diabetic rats the mean for the peak height at around $420 \mathrm{~nm}$ was 135.10 \pm 47.17 . A significant difference was found between these two means $(p<0.001)$. Similarly, the average of the peak height around $446 \mathrm{~nm}$ $(1207.40 \pm 839.38$ vs. $370.10 \pm 271.71, \quad \mathrm{p}<0.05)$ and $467 \mathrm{~nm}(1131.50 \pm 885.02$ vs. $469.90 \pm 270.68$, $\mathrm{p}<0.05$ ) was significantly higher in diabetic rats compared to non-diabetic rats. In contrast, no statistically significant difference was determined between the groups for the peaks at around 490 $(1028.50 \pm 835.03$ vs. $499.90 \pm 245.53, \mathrm{p}=0.134)$ and $520 \mathrm{~nm}(619.30 \pm 488.38$ vs. $341.50 \pm 151.05$, $\mathrm{p}=0.179$ ). In an attempt to characterize the fluorescence of urine by using an excitation of $290 \pm 10 \mathrm{~nm}$, Anwer et al. (2009) reported that tryptophan and its metabolites are the main fluorophores which are excited at this excitation wavelength. In addition, it was reported that the band around $520 \mathrm{~nm}$ may be attributed to riboflavin (Rajasekaran et al., 2014).

The use of an excitation wavelength of $400 \mathrm{~nm}$

From Figure 2(A) it can be seen that the urine emission spectra of non-diabetic rats excited at $400 \mathrm{~nm}$ present six emission bands, as follows: at approximately 450, 486, 525, 555, 578 and 615 $\mathrm{nm}$, respectively. It can also be observed that the urine spectra of diabetic rats (Figure 2(B)) present five emission bands: at approximately 450, 486, 525,555 and $615 \mathrm{~nm}$, respectively.

The mean ( \pm standard deviation) and the $p$ values of the peak height for the urine samples of diabetic and non-diabetic rats are presented
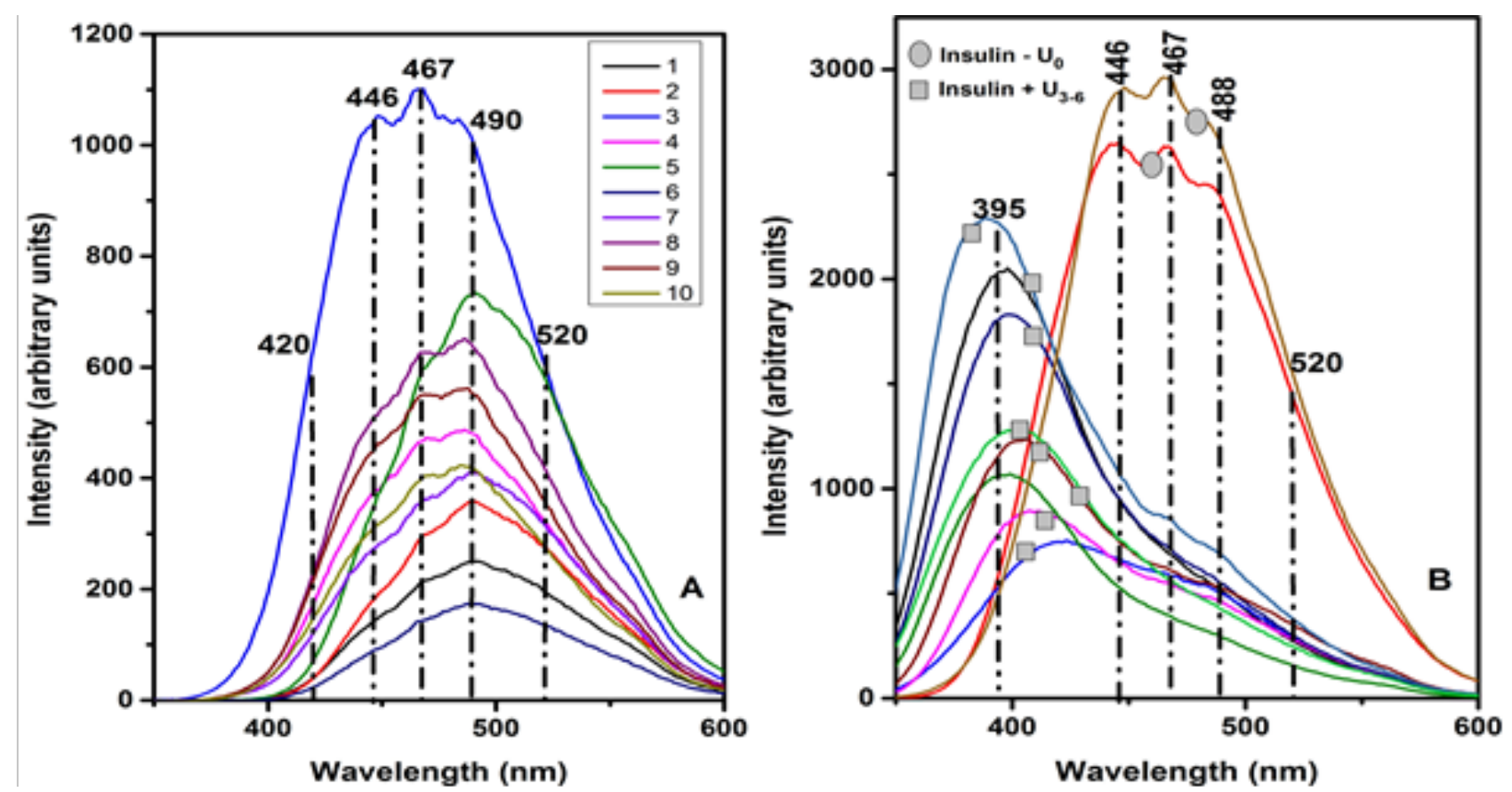

Fig. 1. Urine fluorescence emission spectra of non-diabetic (A) and diabetic rats (B) excited at $280 \mathrm{~nm}$. The spectra were recorded in a range from 350 to $600 \mathrm{~nm}$. 
in Table 1. The $p$ values provided in this table $(p \leq 0.05)$ show a statistical significance for all the investigated variables.

To further attribute the emission wavelengths at the excitation of $400 \mathrm{~nm}$, it has been reported that the peak at $\sim 444 \mathrm{~nm}$ may be attributed to bound NADH (nicotinamide adenine dinucleotide), and the band at $\sim 485 \mathrm{~nm}$ is due to free NADH (Rajasekaran et al., 2013; Masilamani et al., 2010; Wolfbeis and Leiner, 1985). The bands centered at $\sim 525$ and $\sim 615 \mathrm{~nm}$ are mostly due to flavin and porphyrins (Rajasekaran et al., 2013; Masilamani et al., 2010; Wolfbeis and Leiner, 1985).
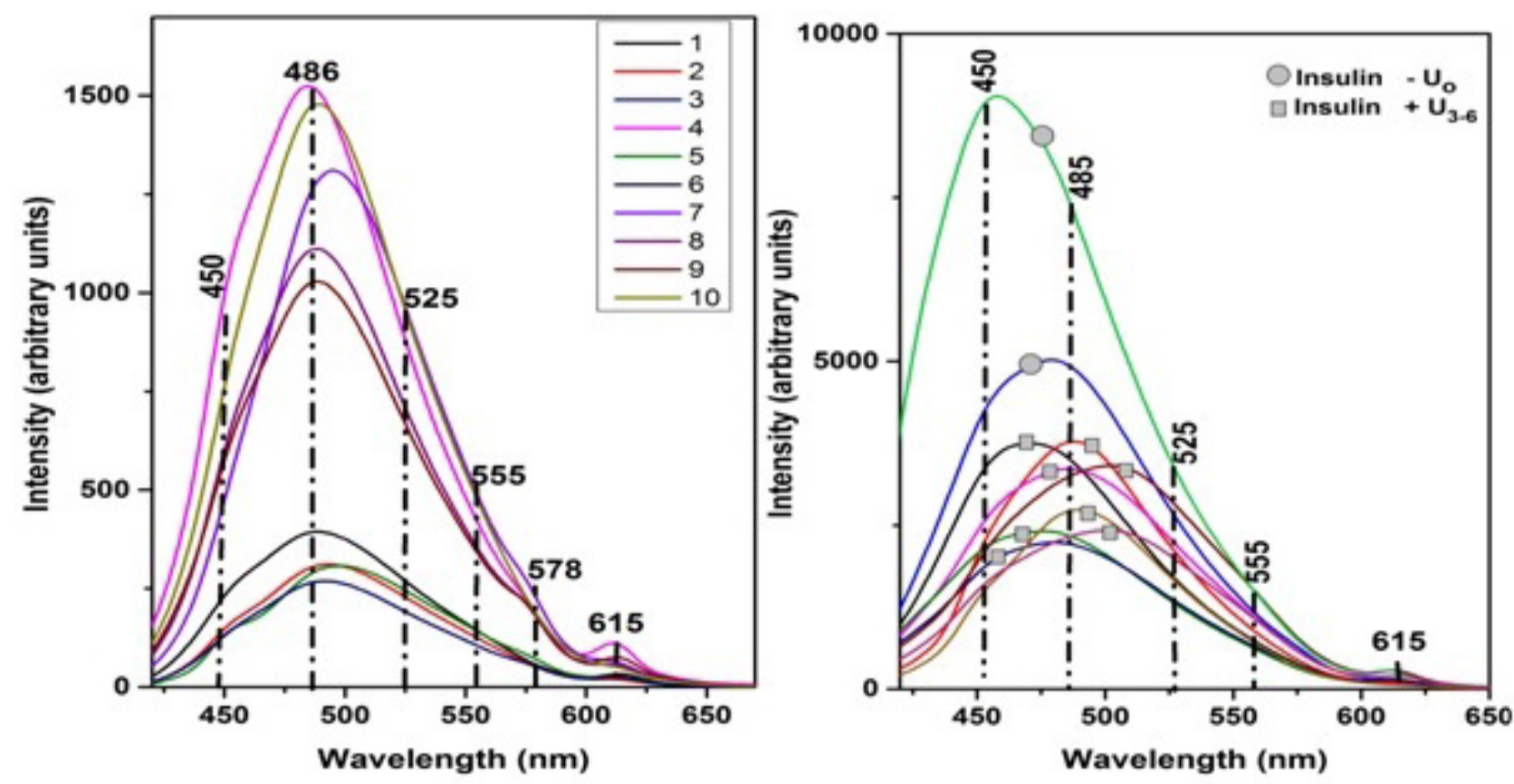

Fig. 2. Urine fluorescence emission spectra of non-diabetic (A) and diabetic rats (B) excited at $400 \mathrm{~nm}$. The spectra were recorded in a range from 420 to $650 \mathrm{~nm}$.

Tab.1. Mean, standard deviation and $\mathrm{p}$ values for the investigated peak height (excitation wavelength of $400 \mathrm{~nm})$

\begin{tabular}{cccc}
\hline $\begin{array}{c}\text { Emission } \\
\text { wavelength }(\mathrm{nm})\end{array}$ & Non-diabetic rats & Diabetic rats & p value \\
\hline 450 & $480 \pm 323$ & $3034 \pm 2266$ & 0.003 \\
\hline 485 & $918.10 \pm 548.504$ & $3619.50 \pm 1540.27$ & $<0.05$ \\
\hline 525 & $503.40 \pm 275.44$ & $2034.40 \pm 644.57$ & $<0.05$ \\
\hline 555 & $228.10 \pm 118.96$ & $959.10 \pm 328.15$ & $<0.05$ \\
\hline 615 & $58.70 \pm 33.24$ & $224.80 \pm 61.53$ & $<0.05$ \\
\hline
\end{tabular}


the fluorescence intensity of free NADH (the band at around $444 \mathrm{~nm}$ ) is affected in diabetic rats compared to non-diabetic rats. This is because the healthy glomerulus of non-diabetic rats can filter the free NADH and therefore, this can be found in urine (Rajasekaran et al., 2013; Gropper et al., 2009). In this context, in the case of non-diabetic rats, the fluorescence of urine is enhanced by the presence of more free NADH. Another important aspect is the small hump around $578 \mathrm{~nm}$ in the spectra of urine samples from non-diabetic rats, which is almost absent in the case of diabetic rats (Figure 2 a,b). Based on the literature data, the peak assignment was not yet possible. This spectral characteristic was also observed in the study of Rajasekaran et al. (2013); the small band at $580 \mathrm{~nm}$ was present in the urine spectra of healthy patients and was absent in the case of diseased subjects.

Fluorescence measurements also show that the emission intensities of urine metabolites before and after insulin administration are higher in diabetic rats compared to controls (Figures $1(\mathrm{~A})$ and $1(\mathrm{~B})$, Figures 2(A) and 2(B)). Moreover, the urine emission spectra of streptozotocininduced diabetic rats (Figures 1(B) and 2(B)) are strongly influenced by insulin administration. Therefore, it can be easily observed that after insulin administration, the emission intensities of urine fluorophores have decreased. The reason for these variations in fluorescence intensity may be the insulin capacity to quench intrinsic protein fluorescence (Bekard and Dunstan, 2009). It was reported that this hypoglycemic agent has three native disulfide bonds in its composition which are responsible for this ability (Permyakov, 1992).

\section{CONCLUSION}

In conclusion, the fluorescence emission spectra excited at 280 and $400 \mathrm{~nm}$ allow making important differences between the urine samples collected from non-diabetic and diabetic rats. Moreover, we could mention an altered metabolism of urine fluorophores (NADH, flavin, porphyrins, indoxyl sulfate) in streptozotocininduced diabetic rats, since their synthesis and excretion are augmented in the case of diabetic rats compared to non-diabetic rats.

\section{REFERENCES}

1. Akbarzadeh A, Norouzian D, Mehrabi MR, Jamashidi SH, Farhangi A, Allah Verdi A, Mofidian SMA, Lame Rad $B$ (2007). Induction of diabetes by Streptozotocin in rats. Indian Journal of Clinical Biochemistry, 22:60-64.

2. Anwer A G, Sandeep PM, Goldys EM, Vemulpad S (2009). Distinctive autofluorescence of urine samples from individuals with bacteriuria compared with normals. Clin. Chim. Acta, 401:73-75.

3. Bekard IB, Dunstan DE (2009). Tyrosine Autofluorescence as a Measure of Bovine Insulin Fibrillation. Biophysical Journal, 97:2521-2531.

4. Dubayova K, Kusnir J, Podracka L (2003). Diagnostic monitoring of urine by means of synchronous fluorescence spectrum. J. Biochem. Biophys. Methods, 55:111-119.

5. Gropper SS, Smith JL, Groff JL (2009). Water-soluble vitamins. In Advance Nutrition and Human Metabolism (Edited by P. Adams, A. Lustig, E. Feldman and E. Downs), pp. 329-333. Wadsworth, Cengage Learning, Belmont, CA.

6. Guptill L, Glickman L, Glickman N (2003). Time trends and risk factors for diabetes mellitus in dogs: analysis of veterinary medical database records (1970-1999). Vet Journal, 165:240-247.

7. Kim YS, Kim NH, Lee SW, Lee YM, Jang DS, Kim JS (2007). Effect of protocatechualdehyde on receptor for advanced glycation end products and TGF-beta1 expression in human lens epithelial cells cultured under diabetic conditions and on lens opacity in streptozotocin-diabetic rats. European Journal of Pharmacology, 569:171-9.

8. Kitabchi AE, Umpierrez GE, Miles JM, Fisher JN (2009). Hyperglycemic Crises in Adult Patients With Diabetes. Diabetes Care, 32:1335-1343.

9. Kušnír J, Dubayová K, Lešková L, Lajtár M (2005). Concentration Matrices-Solutions for Fluorescence Definition of Urine. Analytical Letters,_38:1559-1567.

10. Madhuri S, Vengadesan N, Aruna P, Koteeswaran D, Venkatesan P, Ganesan S (2003). Native fluorescence spectroscopy of blood plasma in the characterization of oral malignancy. Photochem. Photobiol., 78:197-202.

11. Masilamani V, Vijmasi T, Al Salhi M, Govindaraj K, VijayaRaghavan AP, Antonisamy B (2010). Cancer detection by native fluorescence of urine. J Biomed Opt., 15:057003.

12. Perinchery SM, Kuzhiumparambil U, Vemulpad S, Goldys EM (2010). The potential of autofluorescence spectroscopy to detect human urinary tract infection. Talanta, 82:912-917.

13. Permyakov E.A, (1992) editor. Luminiscent Spectroscopy of Proteins.CRC Press, London.

14. Rajasekaran R, Aruna PR, Koteeswaran D, Padmanabhan L, Muthuvelu K, Rai RR, Thamilkumar P, Murali Krishna C, Ganesan S (2013). Characterization and diagnosis of cancer by native fluorescence spectroscopy of human urine. Photochem Photobiol., 89:483-91.

15. Rajasekaran R, Aruna PR, Koteeswaran D, Bharanidharan G, Baludavid M, Ganesan S (2014). Steady-state and timeresolved fluorescence spectroscopic characterization of 
urine of healthy subjects and cervical cancer patients. J Biomed Opt., 19:37003.

16. Saude EJ, Adamko D, Rowe BH, Marrie T, Sykes BD (2007). Variation of metabolites in normal human urine. Metabolomics, 3:439-451.
17. Wild S, Roglic G, Green A, Sicree R, King H (2004). Global prevalence of diabetes: estimates for the year 2000 and projections for 2030. Diabetes Care, 27:1047-53.

18. Wolfbeis OS, Leiner M (1985). Mapping of the total fluorescence of human blood serum as a new method for its characterization. Anal. Chim. Acta, 167:203-215. 